\title{
Fato e ficção em Crônicas de fim do milênio, de Antonio Callado
}

\author{
Ana Paula Macedo Cartapatti Kaimoti
}

\section{Crônicas de fim do milênio}

A partir dos variados traços que poderiam delimitar a crônica como gênero particular de texto, as crônicas de Antonio Callado, publicadas na Folha de S. Paulo e reunidas no livro Crônicas de fim do milênio*, chamaram nossa atenção ao pensar o país e o mundo por meio de uma associação entre obras literárias diversas e o recorte da atualidade oferecido pelo jornal. Baseando-nos nessa relação, observamos que essas obras literárias não se apresentam exatamente como um tema sobre o qual o autor discorre e tampouco como uma evidência de que seus comentários poderiam ser tranqüilamente considerados textos literários.

Nesse procedimento, as crônicas do autor se voltam para a história do Brasil e de outros países, lançando um apelo à memória que manifesta o desejo de repensar o presente e o passado que o constitui. Isso seria feito sobretudo a partir da busca dos limites da identidade brasileira, a qual, na amplitude dessas crônicas, acaba por estender-se à de outros povos. A preocupação com o país, a relação com a história e, nesse sentido, a busca por fixar uma possível memória do Brasil ligam essas crônicas aos romances e reportagens de Callado, bem como estabelecem um diálogo com a trajetória da crônica brasileira.

\section{A crônica de Callado, a crônica brasileira e seus romances: limites e convergências}

A princípio distantes das crônicas de autores como Rubem Braga e Fernando Sabino, por exemplo, e de outros que tomaram emprestados, de forma mais explícita, elementos da narrativa e da poesia, os textos de Crônicas de fim do milênio talvez se aproximassem do ensaio na acepção que lhe deu 
"Coutinho, Afrânio. "Ensaio e crônica". Em: A literatura no Brasil. Niterói: José Olympio, 1986: 105.28; "Literatura jornalismo". Em: A literatura no Brasil. Ob. cit. 57.104.)

(Arrigucci Jr., Davi. “O baile das trevas e das águas". Em: Outros achados e perdidos. São Paulo: Companhia das Letras, 1999: 57.73.)

'(Coutinho, Afrânio. “Ensaio crônica". Ob. cit. "Literatura e jornalismo. Ob. cit.)
Afrânio Coutinho, ${ }^{*}$ paralela ao familiar essay britânico, ou talvez do folhetim inicial de Machado de Assis e José de Alencar, embora não apresentem a longa extensão e o tom anedótico dessa primeira crônica jornalística.

A crônica, sob a perspectiva de sua trajetória no Brasil, a obra geral de Callado e suas crônicas apresentam em comum uma relação com a memória, uma vez que expressam de várias maneiras a preocupação em reter o fluxo dos acontecimentos. Essa busca acompanhou a crônica em sua ascendência quinhentista, quando sua tarefa primeira era a de fixar os feitos dos reinos absolutistas, e marcou sua forma contemporânea e jornalística com a ansiedade diante da passagem do tempo. Na produção ficcional de Callado, essa preocupação resultou num constante embate em face das armadilhas da história, de modo que suas narrativas apresentam uma reescritura da trajetória do país, contando-a a partir dos fatos e situações que teriam sido ocultos ou ignorados pelo relato oficial da história.

Mais que isso, o "corpo-a-corpo cerrado entre os pólos do fato e da ficção", identificado por Davi Arrigucci Jr." nos romances de Callado, permeia a constituição da crônica em geral, resultado de sua vinculação ao elemento histórico e jornalístico, configurando-se particularmente nas crônicas do autor, de forma que nelas se mobilizam as possibilidades de relação entre o texto literário, o fato social e jornalístico.

Nesse sentido, a perspectiva de Afrânio Coutinho* sobre a crônica-texto, que resultaria da reação direta e franca de um indivíduo diante do impacto da realidade, aproxima-se de tudo aquilo que se escreveu sobre o projeto geral dos romances de Callado e expõe a atitude realista comum à crônica e à escrita do autor. Como muitos dos cronistas históricos, ele buscou reter a memória do país refletindo sobre o Brasil e atando, por meio da ficção, sua história remota e recente. Como um cronista contemporâneo, viu sua tentativa de recontar essa história ir de encontro à efemeridade do universo jornalístico, à fragmentação do mass media e ao pequeno espaço nas páginas do jornal.

Para muitos estudiosos da crônica brasileira contemporânea, esse embate com a transitoriedade do jornal seria resolvido por meio da superação do discurso transitivo do jornalismo, presente na crônica, e de sua aproximação com o 
discurso literário. Essa perspectiva parece pressupor que a tessitura que seria própria da obra literária em geral apresentaria uma dimensão permanente, imune à passagem do tempo, enquanto o texto jornalístico teria como característica fundamental a propriedade de ser perecível, padecendo no fluxo dos acontecimentos que o alimentam.

No caso dos romances de Callado, o vínculo com os fatos do jornalismo e da história do Brasil - parte da inquietação do escritor em relação ao país - foi interpretado por meio de dois caminhos principais: aquele para o qual essa atitude realista seria conseqüência de uma relação mais objetiva entre os romances do autor e seu referencial histórico imediato, e outro que encontraria nessa tendência sinuosidades responsáveis pela criação de obstáculos a essa relação, tornando-a menos direta do que parece ser inicialmente.

No primeiro caso, que seria próprio dos críticos iniciais da obra de Callado, como Wilson Martins*, Paulo Hecker Filho*, e Nelson Werneck Sodré*, haveria uma coincidência entre um projeto de escrita que busca pensar sobre determinado dado da realidade e um texto que se relaciona com esse dado de maneira a reproduzi-lo como algo que estaria fora da obra. De forma provavelmente oposta, no segundo caso, há uma nova perspectiva desse projeto para a qual a ficção de Callado seria produtora e não reprodutora de determinada situação do real.

Guardando suas particularidades, esse seria, por exemplo, o ponto de vista de Lígia Chiappini Moraes Leite*, Francisco Venceslau dos Santos* e, em parte, Davi Arrigucci Jr., ao apontar na obra do autor uma postura crítica quanto à possibilidade de suas narrativas serem um retrato de episódios da história do Brasil, o que teria resultado numa visão menos eufórica do país e numa organização narrativa mais intrincada. Sustentando essas discussões parece estar, tanto na crônica brasileira quanto na obra de Callado, a identificação de um caminho duplo que transita entre o universo ficcional e os discursos do jornalismo e da história, os quais teriam um compromisso maior com a descrição de dados da realidade.

Partindo desse contexto, em muitas das crônicas do autor, a duplicidade característica tanto da crônica em geral quanto de sua obra está igualmente presente por meio da inclusão particular de diferentes textos literários em suas
"(Martins, Wilson. "O ópio dos intelectuais", Estado de S. Paulo, São Paulo, n. 553, "(Hecker Filho, Paulo. "O ro. mance justificado". Estado de S. Paulo, São Paulo, n. 594, 1968. Suplemento Literá. rio.)

'(Sodré, Nelson Werneck. "O momento literário", Re. vista Civilização Brasileira, ano III, n.15, p.215.228, set 1967.)

'(Leite, Lígia Chiappini Mo. raes. Quando a pátria viaja: uma leitura dos romances de Antonio Callado. Cuba: Casa de las Americas, 1983.)

'(Santos, Francisco Vences. lau dos. Callado no lugar das idéias. Quarup, um romance de tese. Rio de Janeiro: Caetés, 1999.)

- (Arrigucci Jr., Davi. “O su. miço de Fawcett". Folha de S. Paulo, Caderno Mais!, fev. 1997; "Jornal, realismo, ale. goria: o romance brasileiro recente". Em: Outros acha. dos e Perdidos. Ob. cit.: 77. 109; "O baile das trevas e das águas". Ob. cit.: 57-73.) 
"(Callado, Antonio. Crônicas de fim do milênio. Ob. cit.: 13.) reflexões sobre as manchetes do jornal. Levando-se em conta o que se considera como sendo o projeto de escrita de Callado, a intenção de levar para a obra ficcional os fatos políticos brasileiros sofre, em suas crônicas, uma inversão: à primeira vista, nesse lugar, as obras literárias são a medida do "real" e não o oposto, como se os dados da história e do jornalismo traduzissem o que os textos ficcionais já revelaram sobre o Brasil ou sobre os outros países que ele toma como ponto de partida de sua reflexão.

Nesse sentido, seguindo a interpretação de Arrigucci no ensaio "O baile das trevas e das águas" quanto à relação dos romances de Callado com seu contexto histórico imediato, a presença das obras literárias nas crônicas do autor poderia se constituir como uma alegoria do elemento jornalístico e histórico que serve como marco inicial desses textos, estabelecendo uma relação entre o discurso literário e os fatos da história e do jornalismo, na qual a ficção tende a ser um meio para o conhecimento de um povo.

Na crônica "Japão e Brasil amargam frases de De Gaulle", por exemplo, pode-se encontrar um sinal dessa inclinação no seguinte trecho: "Em que, afinal, reside o segredo da inviolabilidade desse país? Conheço pouco a literatura e a cultura do Japão para propor explicações"*, no qual se expõe a troca de uma perspectiva que entenderia a literatura como reflexo da sociedade pelo seu oposto analógico, aquele que entenderia a sociedade por meio da literatura. A crônica parte de um texto sobre o general francês Charles de Gaulle apresentado na celebração do centenário do general, no qual sua autora analisa as relações de De Gaulle com o Japão, valendo-se do apelido que o general teria dado a um dos primeiros-ministros japoneses, "mercador de transistores", sinal de uma série de complexos que marcaria o povo japonês.

No texto a que Callado se refere, a autora, que é japonesa, expõe a luta de seu povo para reconstruir um país devastado após a Segunda Guerra Mundial. Nesse processo, a necessidade de retomar o desenvolvimento econômico foi priorizada em detrimento das relações familiares e do repouso. Ao privilegiar o trabalho acima de tudo, os japoneses buscavam se auto-afirmar, expondo, segundo a autora, sua síndrome da "pequena potência": um medo histórico de não serem capazes de fazer parte de uma grande nação. 
Callado, então, questiona a possibilidade de esse medo ainda estar presente entre os japoneses já que, naquele momento, o novo primeiro-ministro do país parecia demonstrar, por meio de uma série de atitudes citadas na crônica, a representatividade de sua nação no cenário internacional. Partindo disso, o cronista aponta como uma das características marcantes do país a sua inviolabilidade: a maneira como os japoneses teriam mantido suas tradições e uma identidade própria, mesmo depois das mudanças pelas quais passaram após sua derrota na Segunda Guerra e, particularmente, do papel do governo americano nessas transformações, por terem sido os patrocinadores da reconstrução do Japão.

$\mathrm{Na}$ tentativa de solucionar esse enigma, Callado faz referência a Barthes, que, no livro L'Empire des Signes, teria desvendado muitos dos mistérios do Japão ao constatar que o modo de pensar do povo japonês seria constituído por signos e não pelas palavras e argumentos que fundamentam a linearidade do pensamento ocidental. No haicai, poesia característica do Japão que Callado cita na crônica, estaria particularmente concentrado esse traço da cultura local: “[ [...] signos japoneses que simplesmente flagram e fixam a mensagem do que se passa em torno de um vazio budista - tal como o tráfego intenso de Tóquio ao redor do inatingível vácuo do palácio Imperial”* A força da cultura japonesa estaria nesse vácuo que sobrevive à incorporação do modo de vida capitalista ocidental.

É preciso chamar a atenção para esse ponto do texto. Se, até esse momento, o autor parecia querer compreender o Japão por meio do haicai, o contraste do vácuo zen do palácio imperial em meio a cosmopolita e ocidentalizada Tóquio, somado à resolução seguinte da crônica, indica uma outra interpretação do vínculo estabelecido entre a nação e sua produção literária. Baseando-se na perspectiva de Barthes sobre a poesia japonesa, Callado considera então o apelido que De Gaulle deu ao primeiro-ministro japonês um possível haicai: "Pensando bem, o transistor tem tudo a ver com a emissão de sinais. De Gaulle, dando aquele apelido a Ikeda, estava talvez tentando celebrar, num haicai desajeitado, ocidental, a capacidade tecnológica do Japão"*.

Nesse momento, o haicai deixa de ser um instrumento de interpretação da perspectiva do general e, por extensão, da 
distorcida visão ocidental sobre o Japão, para se tornar a própria fala de De Gaulle, numa fusão criadora de uma segunda possibilidade interpretativa para essa afirmação, na qual se inverte a ofensa, transformada em uma espécie de elogio. Além disso, é interessante observarmos que Callado redimensiona o provável equívoco de um francês, De Gaulle, a partir da perspectiva de um conterrâneo do general, Roland Barthes: "Mas houve, em nossos dias, um francês que desvendou, a meu ver, muito da alma japonesa. Não se trata, é claro, de Charles de Gaulle, e sim de Roland Barthes"*.

Mais que isso, toda a construção desse pensamento serve à preocupação de Callado quanto à sua própria nação, ponto que se mostra, inicialmente, no título da crônica. No princípio do texto, Japão e Brasil são colocados lado a lado, segundo o ponto de vista que De Gaulle demonstrou em relação aos dois países por meio de "frases afiadas como facas". Mas se, para Callado, a crítica do general aos japoneses se redime na possibilidade de um haicai, em relação ao Brasil a recíproca não é verdadeira: o cronista não acredita ser possível encontrar uma outra interpretação para a fala de De Gaulle sobre o país e finaliza a crônica com sua dúvida: “[...] haverá duas interpretações para o dito [do general francês] de que o Brasil não é um país sério?”**.

Nesse irônico ponto de interrogação, encontramos o Brasil por trás do Japão, que parecia ser o horizonte principal da crônica. Do final, voltamos ao início do texto e, no sentido dessa analogia, este ganha outras dimensões. Ao lado do sóbrio haicai japonês e de sua busca pelo fim da linguagem, as retóricas ocidental e, principalmente, brasileira ecoam superficiais e duvidosas na fala de De Gaulle. Nesse sentido, a força e a inviolabilidade da cultura dos aparentemente pequenos japoneses em face do pensamento ocidental flagram a porosidade da América subdesenvolvida diante da força econômica e cultural do chamado primeiro mundo. A equivocada síndrome japonesa da pequena potência ressoa na esperança frustrada dos brasileiros em relação a um país que dará certo, o Brasil gigante, porém eternamente localizado num futuro cada vez mais remoto.

As relações que o texto estabelece entre Ocidente e Oriente, Brasil e Japão, portanto, pautam-se especialmente numa fina ironia que tece níveis diferentes e sutis de interpretação, 
manipulando a aparência dos fatos históricos e a possibilidade de reinvenção desses dados. Nesse contexto, o haicai tem papel fundamental, ao mostrar-se simultaneamente como símbolo da resistência japonesa, alegoria de sua capacidade de ser grande e, na tessitura da crônica, como agente da inversão e do redimensionamento que o tex to promove do olhar do Ocidente sobre o Oriente e do olhar do Brasil sobre si mesmo, passando de referência textual a agente gerador de sentido.

Em "Hitler criou na Amazônia o Estado de Israel", a função do texto literário presente na crônica também se mostra de maneira dúbia. Partindo de matérias publicadas na própria Folha de S. Paulo sobre o neonazismo, na primeira crônica, Callado trata dos alemães e de Adolf Hitler tomando como caminho para sua reflexão um romance do escritor alemão George Steiner: "Para, na medida do possível, entender a pouco inteligível Alemanha dos tempos nazistas, tenho me valido de George Steiner [no caso, do romance The portage to San Cristobal of A. H.]". Nesse trecho, o cronista deixa clara sua intenção de usar a obra como um meio de entendimento da história da Alemanha.

Contudo, ao notar que no romance The portage to San Cristobal of $A$. H. haveria um certo desleixo quanto à geografia e ao léxico brasileiro a que o livro faz referência, Callado apresenta uma perspectiva diferente daquela na qual o apelo ao romance seria um instrumento para a compreensão do comportamento dos nazistas na Alemanha, durante a Segunda Guerra: "Mas o romance de Steiner não é feito de acidentes geográficos, e sim de iluminações e alucinações, e a própria Amazônia para onde os judeus trazem Hitler, que não morreu em Berlim (foi um sósia), é uma região mental”*.

Esse trecho indica na obra menos uma reprodução de um fato histórico e mais uma reescritura de um episódio por meio da ficção, na qual se revelariam outros sentidos do mesmo. Diante disso, perguntamo-nos se, nas crônicas, os outros países e o Brasil não se constituiriam freqüentemente como uma região mental, construída a partir das obras que formam a memória literária do autor. Muitas das crônicas apontam para uma orientação dupla, a apresentação concomitante de um projeto de escritura que procura entender a nação por meio das obras literárias, criando um vínculo inicialmente ins- 
trumental entre esses elementos, bem como uma efetivação desse plano que acaba por criar brechas naquela direção inicial, entendendo o fato social juntamente com essas obras.

Desse modo, esses textos apresentam uma relação entre o discurso histórico, o discurso jornalístico e o discurso literário, na qual o último se mostra principalmente em sua potencialidade crítica. Nesses momentos, a memória literária do autor assumiria um papel mais ativo, reorganizando a reflexão, a ponto de oferecer outras possibilidades de interpretação para os fatos históricos e jornalísticos, ao mesmo tempo em que às próprias obras se acrescentam outros significados. Nesse sentido, essas crônicas, assim como chamam a atenção para o que estaria, a princípio, fora do texto - no espaço reservado aos acontecimentos da história, mesmo os que foram esquecidos, e aos do jornalismo -, fazem-no a partir de um movimento para dentro - aquele no qual se cria a relação peculiar entre as obras literárias e a busca, tão marcante na obra do autor, pela origem do brasileiro, sua identidade.

\section{Mais duas crônicas: "Doudos ocupam Brasil, Portugal e Algarves” e “É necessário trancar Nelson no teatro"}

No rés-do-chão da crônica, "Doudos ocupam Brasil, Portugal e Algarves" parte de um fato do cotidiano, da esfera dos acontecimentos da época: o congresso que reuniu portugueses e brasileiros para discutir a reforma ortográfica da língua. A partir desse ponto, há uma retomada da memória histórica presente nas palavras que os portugueses trouxeram para o Brasil, as quais haviam sido recolhidas por eles em outras paragens, como a Índia e a África, durante as navegações. Nesse sentido, Callado cita termos como "bangalô", "aia" e "caril" - palavras que estariam em desuso na língua portuguesa corrente - para chegar àquele que é o mote da crônica: "doudo", considerado pelo autor como uma palavra especialmente representativa da identidade portuguesa e brasileira.

Callado investiga, então, os possíveis significados dessa palavra, a qual, no decorrer da crônica, torna-se o guia de uma trilha que percorrerá a memória literária do autor. As obras presentes no texto parecem, assim, desdobrar os limi- 
tes do termo, a ponto de torná-lo simultaneamente uma porta de entrada para o retorno à história de Portugal e uma trilha por meio da qual se estabelece a ligação entre a trajetória das navegações portuguesas, o estabelecimento do Brasil e seu presente.

Esquecido pelos falantes da língua portuguesa e extinto no choque de seu encontro com os portugueses na ilha Maurício, seu habitat original, o doudo, segundo Callado, teria adquirido "vida e fama eterna" ao fazer parte do grupo de animais que povoa a narrativa Alice no país das maravilhas de Lewis Carrol. A partir desse lugar, no qual a ave se manteria viva, nasce na crônica uma outra imagem, formada pela justaposição do doudo encontrado pelos navegadores de Portugal, na ilha Maurício, com o espelho de Alice e o doudo do país das maravilhas. "A ilha foi posteriormente ocupada e colonizada pelos holandeses, mas os primeiros navegantes que nela pisaram foram os portugueses, que lá se viram diante do doudo. Era como se eles, portugueses, fossem uma pré-Alice e vissem a própria imagem futura dentro de um espelho"*.

'(Callado, Antonio. Crônicas de fim do milênio. Ob. cit.: 4.)

Diante do espelho dessa Alice, os portugueses nem ao menos suspeitam do prenúncio que seu estranho reflexo anunciaria. Essa imagem se mostra primeiramente, segundo as palavras do autor, cômica e caricatural. A estranheza do doudo estava na desproporcionalidade de suas pequenas asas em relação ao corpo avantajado e em seu bico torto. Ao ver a ave, os marinheiros portugueses riem e chamam-na de "doudo", criando, assim, seu nome. A partir daí, a crônica percorre as várias formas e possibilidades de acepção da palavra num trajeto que adentra mais um pouco na memória literária do autor. Doida como os personagens do livro de Carrol, caricatura de Portugal, a ave, em seu caráter simbólico, não poupa sequer Camões, o consagrado representante da nação portuguesa:

E o curioso pássaro que Alice encontra ao seguir o Coelho terra adentro, é doudo de pedra, já que todos atendem à doidice no País das Maravilhas. São doidos, como Camões, que não podia ver mulher sem se endoidar ou endoudecer: "[...] branca Tétis, única despida: / como doudo corri de longe, abrindo/ os braços, para aquela que era vida/ deste corpo"*. 
No contexto da crônica, já não se vê Camões correndo como doido ao encontro de sua amada, mas como um doudo, desajeitadamente. Neste trecho, Callado explora as várias formas da palavra de maneira explícita, disseminando-a pela crônica, de modo que o doudo inicial ganha em imagem e forma, "doudo" esquecido pela língua portuguesa e que habita o país de Alice e a ilha Maurício, "endoudecido" e "endoidecido", "doido", enfim, em Camões. Ao assumir todas essas facetas, a ave se torna então o doudo do próprio texto: doido, português e brasileiro.

Antes de chegar ao Brasil, porém, Callado leva o doudo até Baudelaire, posicionando-o ao lado do albatroz, personagem de um soneto desse poeta no qual a ave se encontra aprisionada por marinheiros em um navio. Enquanto o doudo não conseguia alçar maiores vôos em razão de suas asas excessivamente pequenas - o que o tornou uma vítima fácil dos roedores e outros predadores que acompanharam os portugueses em seus navios até a ilha Maurício -, o albatroz não consegue andar - sua única possibilidade de locomoção depois de preso - por causa de suas asas, grandes demais para o corpo.

Na medida dessa desproporção, o gigante de Baudelaire se inverte no anão dos portugueses, constatação que torna ainda mais representativa a associação dos doudos com Portugal. De albatroz a doudo, Portugal cresceu demais e perdeu a capacidade que o tornou notório, aquela que o levou à exploração do Novo Mundo, por ser ainda pequeno para o tamanho de sua conquista. Acabou extinto por outros povos mais competitivos e obrigado a paralisar o ciclo das descobertas.

Rebento do doudo português, o Brasil, na crônica, representa sua linhagem por meio da incapacidade em fazer prosperar as dimensões tão avantajadas que adquiriu especialmente após o Tratado de Tordesilhas. Dessa forma, as asas brasileiras parecem pequenas demais para o tamanho do corpo, e nem mesmo os exploradores de nossa capacidade de voar, Bartolomeu de Gusmão, com sua passarola, e Santos Dumont, com os primeiros aviões, livrariam o Brasil de sua doudice. "Não progredimos nada, em termos de asas. Deixamos que elas encolhessem. Viramos, também, o doudo que somos hoje"*. Diante disso, o doudo, para Callado, pode ser eleito o símbolo primeiro de uma raça trôpega e inchada, no- 
meação que seria, para o Congresso, tarefa mais útil que discutir as regras ortográficas da língua portuguesa.

Nesse processo pelo qual o doudo passa de ave extinta para símbolo dos portugueses e brasileiros, a memória literária de Callado constrói um olhar sobre a história de Portugal e do Brasil que se mostra renovado ao ligar as narrativas do cotidiano, da história e da literatura, e criar um mapa de busca pela origem do país e sua identidade. Por meio de um embate com o esquecimento, esse retorno se dá com base sobretudo em uma visão crítica e irônica do passado e do presente.

$\mathrm{Na}$ crônica, parte-se da ave para a época do descobrimento, quando Portugal parecia ser uma Alice aventureira, sem saber que sua procura pelas maravilhas do Novo Mundo se tornaria uma epopéia disfórica em direção a si mesma. Chegando à contemporaneidade, no momento primeiro da crônica, a busca de Portugal ainda se mostra incompleta, tendo contaminado suas antigas colônias, e, nelas, os lusobrasileiros. Nesse sentido, o espelho que leva ao país criado por Lewis Carrol parece condensar em si mesmo a função que as obras literárias assumem nessa crônica: ao ultrapassar o seu uso corrente como refletor fiel de uma imagem, ele se constitui como revelador de aspectos ocultos da mesma.

Mais que meios passivos para o entendimento de Portugal e do Brasil, os textos e imagens literárias se tornam reorganizadores da trajetória em comum dessas nações e da crônica como um todo. Mensageira dessa viagem, a palavra "doudo" se encontra no texto de tal modo disseminada e potencializada em suas possibilidades de imagem, forma e significado, que se torna o principal motor de sentido da crônica, ponto a partir do qual partem os caminhos que levam da língua portuguesa ao País das Maravilhas, do universo de Alice à ilha Maurício, da escrita de Camões a Baudelaire e, finalmente, ao horizonte principal de Callado, o Brasil.

Esse mesmo funcionamento ostensivo da memória literária está presente na crônica "É necessário trancar Nelson no teatro". No título, pode-se encontrar um apelo e uma pergunta que seria conseqüência dele: qual o motivo para trancar Nelson, o de sobrenome Rodrigues, no teatro, se esse já seria o lugar de sua obra? A resposta a essa pergunta parece ser a própria motivação da crônica: para Callado, a obra de Nelson estaria muito além dos palcos, disseminada na vida 
política e cotidiana do país. Essa consideração anuncia explicitamente o que, no parágrafo seguinte, parece estar transmutado na escrita do texto.

Sem ser previamente apresentada, uma narrativa se faz presente e conta a história de um "chefe de família", Vicente Cimino, que assassina seus próximos em meio a um jantar de Natal, entregando-se à polícia logo depois:

No dia 24 de dezembro passado, Vicente Cimino, um construtor paulista, tinha ceia de Natal em casa. Recebia, ao lado da mulher Maria Tereza, os pais dela e mais um primo e dois sobrinhos. Vicente estava, como ficou estabelecido depois, bem-disposto, alegre. Pouco antes de servida a refeição, Maria Tereza atendeu o telefone e ficou de palestra. Como essa conversa se estendia um pouco demais, Cimino foi ao armário onde guardava, escondido, um revólver, e começou, pela mulher, o extermínio. Depois de disparar, nela, dois tiros, atirou no sogro, na sogra e no sobrinho. No meio da chacina, e depois de carregar de novo a arma, baleou o primo, que aliás foi o único a escapar com vida, ou só com uma bala na barriga. A cena terminou naquilo: quatro mortos. Cimino então chamou a polícia pelo telefone e quando chegaram os policiais entregou a arma, entregou a si mesmo, com alívio, depois de informar, como quem não quer dar trabalho a ninguém: "Acabei de matar minha família"*.

Instalada a proximidade, não parece ser possível diferenciar, nesse trecho da crônica, a descrição de uma notícia da sinopse de alguns dos textos de Nelson, nos quais, de forma geral, também se encontram personagens em situações-limite, sob a fina camada do cotidiano. Porém, logo depois, quando Callado afirma que essa história lhe trazia à memória alguma cena do dramaturgo, estabelecem-se os limites e pode-se perceber que a narrativa falava sobre um fato do jornalismo policial, algo do âmbito do vivido.

Esperando, então, a citação dessa cena de teatro, o leitor se depara com cenas da história política nacional, ligadas à crise pela qual havia passado recentemente a família Collor. "Faltaram os disparos, é bem verdade, na espécie de extermínio da família realizado por Pedro Collor em meados de 1992, mas a destruição que ele promoveu foi igualmente radical"*.

Eram cenas vividas que acudiam à memória de Callado, que acredita que a escrita de Nelson Rodrigues e os fatos da vida cotidiana e política do país se confundem em sua memória. "Assim, quando a gente pensa, diante de um crime 
comum como o de Vicente Cimino, que se está lembrando de alguma cena de peça de Nelson Rodrigues, está na verdade rememorando uma página da história política do Brasil”**

$\cdot(: 28$.

- (Mello, Pedro Collor de. Passando a limpo. A Trajetória de um Farsante. Rio de Janeiro: Record, 1993.)

Farsante*. "A crise da família Collor é transcrita em termos de Os sete gatinhos ou Senhora dos afogados. Dos irmãos, Pedro só salva Ana Luiza. Os demais, Fernando, Leopoldo e Ledinha, são todos da laia do já citado Palhares, o canalha de Nelson"*. Esses termos parecem ser especialmente aqueles ligados à hipocrisia, ao falso moralismo e à violência velada que permeariam a rotina política brasileira. O discurso autobiográfico de Pedro Collor se torna uma narrativa de Nelson e os membros da família, personagens de uma peça vivida:

A partir do momento em que dona Leda foi internada, em setembro de 1992, os choques familiares não só aumentaram como resultaram em diálogos de pura rodriguésia. [...] Pouco depois, Leopoldo entra em cena contra Ana Luiza, no Hospital Albert Einstein. Sem cumprimentar a irmã, disse logo cheio de ironia: "Quer dizer que você não queria que mamãe viesse para São Paulo, hein?” Ana Luiza ficou calada e Leopoldo então atacou: "Você não pode decidir nada, você não é nada. Para mim, Ana Luiza, você vale tanto quanto o esgoto do rio Tietê"**.

Para Callado, a proximidade entre o cotidiano nacional e a obra de Nelson explicaria a unanimidade atual da crítica literária em torno desse autor: sua escrita se teria confundido misteriosamente com a história do país. Mas para o cronista esse não deveria ser o Brasil: “[ $[.$.$] as obras que retratam$ uma nação, todo um povo, são em geral grandes e variadas, como a Comédia humana de Balzac ou a coleção de romances de Dickens. O modelo de Nelson é obcecado, restrito. Seu Vestido de noiva fica apertado demais para o país inteiro"*.

Chama a atenção o verbo "retratar" utilizado por Callado, pois assume textualmente a possibilidade de uma obra ficcional reproduzir a experiência de uma nação. A despeito disso, o autor restringe a possibilidade de a literatura de Nelson representar dessa maneira o Brasil. Diante disso e considerando que todo o movimento da crônica se estrutura na ligação entre esses dois elementos, perguntamo-nos, então, que espécie de representatividade essa obra teria, no texto, em relação ao país.

Essa crônica é provavelmente uma das únicas na qual não há a citação de trechos de alguma obra ficcional, no caso,
'(Callado, Antonio. Crônicas de fim do milênio. Ob. cit.: 28.) 
"(Arrigucci, Davi. "Fragmen tos sobre a crônica". Em: Enigma e comentário. São tras, 1987: 51.66.) de Nelson Rodrigues. Callado, no entanto, além de descrever a notícia sobre Vicente Cimino, cita várias passagens do livro de Pedro Collor, no qual este descreve a relação conturbada entre os membros de sua família. Parece que, em razão da simbiose encontrada pelo cronista entre as peças de Nelson e a vida política brasileira, a presença explícita do texto rodriguiano se teria mostrado tão desnecessária que a notícia do jornal e a história da família Collor se tornaram a própria escrita de Nelson, dispensando maiores apresentações do autor em relação à obra que organiza sua reflexão. Dessa maneira, a crônica, ao lançar mão dos escritos de Nelson, tornando mais veemente a face torpe da história recente do país, cria uma nova perspectiva em relação a ela, estabelecendo um novo mapa de possibilidades de sentido para uma história que naquele momento ainda se fazia.

\section{O mapa de um Brasil imaginário}

A partir da investigação da presença da literatura nas crônicas de Antonio Callado, observamos que sua obra e a trajetória da crônica brasileira se conectam às crônicas do autor principalmente por meio de um projeto implícito de escritura em que, guardando as particularidades de cada um, o texto estaria fundamentado inicialmente no que seria seu referencial histórico ou jornalístico imediato. Mais que isso, a conexão se torna evidente ao notarmos que essa espécie de marca realista comum seria desorganizada pela ligação desses três conjuntos de textos com o universo literário, o que teria criado em todos eles um descompasso entre a expectativa inicial de escritura e sua concretização.

Para o cronista contemporâneo, segundo a maior parte dos críticos, a busca pela organização ficcional do texto seria uma maneira de escapar ao caráter efêmero do jornal, como se a perenidade fosse um aspecto intrínseco ao literário. Em trecho do artigo "Fragmentos sobre a crônica"*, Arrigucci parece considerar que na crônica, entre o fato jornalístico que lhe serve de ponto de partida e sua forma final como texto, haveria um caminho direto o suficiente para torná-la um meio para o entendimento de um país no qual, particularmente a partir da década de 1930, o desenvolvimento industrial e urbano se teria intensificado. 
Seguindo a tendência do momento e de outros gêneros, a crônica se convertia num meio de mapear e descobrir um país heterogêneo e complexo, largamente desconhecido de seus próprios habitantes, caracterizado pelo desenvolvimento histórico desigual [...]. Por isso, muitas vezes ela se volta para o passado colonial, retomando sua antiga forma histórica para recuperar retalhos da memória da nação.*

Nesse sentido, ao falar sobre a crônica-folhetim, Arrigucci a considera igualmente uma espécie de registro das transformações pelas quais o Brasil passa desde o fim do século XIX e um reflexo de suas contradições, as quais, segundo o autor, exigiam freqüentemente do cronista, em busca por entendêlas em sua disparidade, o tratamento artístico do fato. Nesse ponto, o crítico parece aproximar a crônica brasileira contemporânea do ofício principal da crônica histórica, o de registrar; porém, em seu último formato, a crônica se ateria ao fato recente no lugar de se voltar para o passado.

No entanto, assim como a crônica histórica ultrapassou essa função objetiva ao se apropriar de elementos da narrativa ficcional, a crônica contemporânea, ao tomar para si os mesmos elementos, parece ter configurado uma outra forma de tratamento do fato, diferente daquele dispensado pelo texto jornalístico. Desse modo, na crônica o foco de interesse não seria tanto o assunto, o fato sobre o qual escreve o cronista, mas sim a maneira como ele constrói o texto.

Essa pode ser uma das razões para que seu tema principal se tenha tornado o pequeno acontecimento cotidiano, o qual não tem importância factual para o jornal. Assim, o cronista contemporâneo se aproximaria do cronista histórico não apenas em seu projeto inicial de registrar os fatos, mas também na possibilidade de reorganizá-los por meio de um olhar subjetivo, redimensionando-os e proporcionando novos ângulos de interpretação sobre os mesmos.

Essa tensão entre o fato e a ficção, como vimos, está presente na escrita de Antonio Callado e seria conseqüência de seu projeto de passar a história do Brasil para seus romances. Como resultado, sua escrita foi interpretada como realista de acordo com duas perspectivas principais, aquela na qual esse realismo seria reprodutor do dado histórico e jornalístico e aquela na qual ele seria produtor desse dado, elaborando 
"(Leite, Lígia Chiappini Mo. raes. Quando a pátria viaja: uma leitura dos romances de Antonio Callado. Ob. cit.: 27. uma alegoria do elemento histórico ou apropriando-se do mesmo para recontá-lo, iluminando-o por meio da ficção.

Nesse sentido, Lígia Leite encontra na escritura do autor a possibilidade de o país ter se tornado menos um referente posicionado fora do texto e mais uma região mental, especialmente como resultado de um questionamento em relação à possibilidade de a narrativa abarcar efetivamente uma experiência do âmbito vivido. Parece provável que, por força dessa construção particular, a ficção do autor se tenha revelado o avesso da história, redescobrindo-a, como expõe no seguinte trecho:

A ficção como o avesso da história e a ficção como a forma de “revelação e conhecimento do país”, o projeto romântico, é ainda o projeto de Callado que, como Gonçalves de Magalhães, Gonçalves Dias, como Oswald de Andrade ou Graça Aranha e, como hoje, Fernando Gabeira (para nomear só alguns) no exílio e a partir dele, redescobre o Brasil.*

Diante disso, nesses dois conjuntos de textos, a crônica e a obra geral de Callado, a relação estabelecida entre a ficção e o fato mobiliza os limites do que seria literário, jornalístico e histórico, trazendo à tona o problema das formas de relação entre esses discursos. Conseqüentemente, esse vínculo levanta a possibilidade de o discurso ficcional funcionar como um reorganizador dos dados da história e do jornalismo, ao oferecer interpretações diferentes desses dados.

Nas crônicas de Antonio Callado, esse aspecto se mostra de forma singular. Nelas efetivamente há momentos em que a ficção - por meio da memória literária do autor - torna-se responsável pela construção do sentido do texto como um todo. Assim, o projeto realista do autor se concretizaria em suas crônicas de maneira a estabelecer uma outra forma de relação entre o texto ficcional e aquele que seria factual e passível de comprovação de verdade, diferente de um plano inicial de escritura em que as obras literárias seriam a medida do real, servindo como instrumentos para a compreensão de um determinado povo ou nação. Esse propósito seria desestruturado pela presença da literatura, aspecto que nos interessou particularmente e que foi o tema central deste estudo.

No sentido daquela revelação, apresentada por Lígia Leite na passagem citada, essa ligação apresenta a ficção principalmente como iluminadora dos dados da história. Por meio 
de seu potencial crítico revelador, os textos literários que constituem a memória de Callado seriam como um espelho dos fatos jornalísticos e históricos no sentido mesmo em que funcionaram o espelho maravilhoso de Alice, no qual se viram os portugueses na crônica "Doudos ocupam Brasil, Portugal e Algarves". Como o doudo, a ave da crônica citada se torna uma ave-espelho, e a obra de Nelson Rodrigues, na crônica "É necessário trancar Nelson no teatro", funcionaria como esse espelho ao tornar mais grotesca e caricatural a história política recente do país.

Esses elementos literários não funcionam no texto como reprodutores de uma imagem, mas como reveladores de aspectos ocultos da mesma, servindo como ponte entre o passado e o presente, constituindo-se como dispositivos por meio dos quais Callado, como descrito por Francisco V. dos Santos* em relação aos romances do autor, tornaria o atual um "ponto flexível do tempo", a partir do qual a história do Brasil - no caso das crônicas, de outros países - seria revista sob os fragmentos da contemporaneidade.

Desse modo, em sua possibilidade de ser crônica, o texto do autor atesta de forma mais dramática a ligação que a crônica parece ter sempre estabelecido entre o fato e a ficção. Como crônica-ensaio, inicialmente livre das convenções do gênero literário ou jornalístico, há nele uma conjunção tensa entre esses dois pólos. Essa conjunção direciona o olhar do leitor para dois caminhos: um primeiro, dirigido aos dados históricos e jornalísticos, e um outro, por meio do qual se forma um novo desenho textual, em que o texto reconhecido como literário está unido àquele da experiência.

Nesse procedimento, a crônica se torna não um meio de mapeamento do país - como Arrigucci disse ser a crônica brasileira modernista -, mas o próprio mapa, região textual e mental em que habitam doudas Alices portuguesas e haicais americanos, entre outras imagens que talvez formem a narrativa de uma viagem que tem como destino principal um Brasil imaginário. Assim, a presença dos textos literários junto aos fatos e a relação que se estabelece entre eles voltam à atenção inusitadamente para o próprio texto, sem deixar de apontar para os acontecimentos vários da história e da imprensa, porém fazendo da linguagem seu caminho principal. 
Ao serem trazidos para a crônica, os fatos jornalísticos e históricos se tornam tão maleáveis ao olhar do autor quanto os textos literários dos quais ele lança mão, tornando-se menos um dado da realidade que um dado textual, um elemento da engrenagem da crônica. Por isso, mais que o próprio fato que lhe serviu de mote, a crônica ganha a possibilidade de se tornar o fato que interessa. Finalmente, nessa forma de relação entre o texto literário e os elementos históricos e jornalísticos, a memória literária do autor não só adquire a função de desvendar a trajetória do Brasil e de outros países, como se faz presente principalmente por meio de seu potencial crítico, revelando, no mínimo, a capacidade desse texto de reelaborar o lugar do literário em face dos fatos da vida humana. 
Ana Paula Macedo Cartapatti Kaimoti

Mestre em Teoria da Literatura pelo Instituto de Biociências, Letras e Ciências Exatas, da Unesp. Seu artigo "A presença da história em Reflexos do baile, de Antonio Callado" foi aceito pela Revista de Letras da Unesp e deverá ser publicado no próximo número da revista. Nesse momento, é doutoranda e bolsista do CNPq, matriculada no Programa de Pós-Graduação em Teoria da Literatura do mesmo Instituto, na linha de pesquisa Perspectivas Teóricas no Estudo da Literatura, sob orientação do prof. Dr. Marcos Antonio Siscar.

\section{Resumo}

Ao examinar os textos de Antonio Callado publicados na Folha de $S$. Paulo e reunidos no livro Crônicas de fim do milênio (1997), buscamos investigar de que maneira Callado lança mão de textos literários diversos para constituir seu ponto de vista nos comentários que faz sobre os dados do jornalismo e da história. Mais que uma ilustração do conteúdo das crônicas, essas obras apresentam-se como organizadoras de sua argumentação, revelando-se como um dispositivo de descoberta do mundo, por meio do qual o autor revê a história do Brasil. Nesse contexto, este trabalho aborda a trajetória da crônica brasileira e a obra geral de Antonio Callado, as quais apresentam um ponto fundamental de convergência com as crônicas do autor: a vinculação entre o texto literário, os fatos jornalísticos e os dados históricos, aspecto que se constitui como um dos eixos centrais de nosso estudo.

\section{Abstract}

Antonio Callado is known as an author who aimed at reflecting on recent Brazilian history in his writings. Our purpose is to analyze how several references to literary texts are incorporated in the weekly commentaries about journalistic facts and history, which were first published in the newspaper Folha de S. Paulo and later in the book Crônicas de fim do milênio (1997). First, we did not treat such references as mere illustrations of the content in these texts. Furthermore, as an important part of the whole text, these references to literary works

\section{Resumen}

Analizando los textos de Antonio Callado, publicados en el periódico Folha de S. Paulo, y reunidos en el libro Crónicas del Fin del Milenio (1997), buscamos saber como Callado desarrolla textos literarios diversos para constituir su punto de vista en los comentarios que hace sobre los datos del periodismo y de la Historia. Mas que una ilustración del contenido de crónicas esas obras se presentan como organizadoras de su argumentación, se rebelando como un dispositivo de descubierta del mundo, por cual el autor revé la Historia de Brasil. En este
Palavras-chave

Antonio Callado

Crônicas de fim do milênio

crônicas brasileiras

jornalismo e literatur

história e literatura

Key words

Antonio Callado

Crônicas de fim do milênio

Latin American studies

journalism and literature history and literature

Palabras llaves

Antonio Callado

Crônicas de fim do milênio

crónicas brasileñas

periodismo y literatur

historia y literatura 
became a way to enlighten and review Brazilian history. Through the link between Callado's chronicles, his novels and the history of the Brazilian chronicle, it's possible to make connections between literature, history and journalism: a central axis of our analysis and the reason why Callado's other literary texts as well as the chronicles are included in our study. contexto, este trabajo aborda el camino de la crónica brasileña y la obra general de Antonio Callado las cuales presentan un punto fundamental de convergencia con las crónicas del autor: el vinculo entre el texto literario, los factos periodísticos, aspecto que se constituye como uno de los puntos centrales de nuestro estudio. 